\title{
A Study of Semantic Clash in Skit-Humor within the Framework of Co-Selection
}

\author{
Lele Sun \\ School of Foreign Languages, Jiangsu University of Technology, Changzhou, China \\ Email: anothersunnie@hotmail.com
}

How to cite this paper: Sun, L. L. (2020) A Study of Semantic Clash in Skit-Humor within the Framework of Co-Selection. Open Journal of Social Sciences, 8, 91-113. https://doi.org/10.4236/jss.2020.85007

Received: April 13, 2020

Accepted: May 10, 2020

Published: May 13, 2020

Copyright $\odot 2020$ by author(s) and Scientific Research Publishing Inc. This work is licensed under the Creative Commons Attribution International License (CC BY 4.0).

http://creativecommons.org/licenses/by/4.0/

\begin{abstract}
Co-selection is the core mechanism of language description in corpus linguistics. Within its framework, this study tries to explore the distribution of punchlines in skit-humor and investigates the phraseological features of verbal humor, which is the main part of skit-humor in the skits, to find out the semantic clash. The categories of punchlines in the skits could be broadly classified into verbal humor and nonverbal humor. Verbal humor accounts for the majority of the punchlines in the skits. It is believed that semantic clash is the primary factor for verbal humor which may elicit laughter. Chinese verbal humor in the skit-humor could not be transferred into English because the controversial attitude is lost in the process of conversion. This, in turn, indicates that the semantic clash may contribute essentially to the punchlines in Chinese skit-humor. Relexicalization is one of the fundamental linguistic process in appreciating humor and offers the basis of a powerful and elegant explanatory hypostudy. It describes how humor depends upon the interplay of the phraseological and the open-choice language principles, the sudden shift from the first to the second.
\end{abstract}

\section{Keywords}

Semantic Clash, Co-Selection, Skit-Humor

\section{Introduction}

Humor, as a special phenomenon, is the essence of human languages and cultures, which is pervasive in all sorts of human communication. The early explanations and studies of humor could have been dated back as far as Greeks, from Plato and Aristotle, through Kant, to the more recent Bergerson and Freud. Because it has been playing a vital role in the interaction of human beings, humor brings delight to the receivers and also conveys the humorist's intentions, such 
as mockery or teasing. Being a reflection of one's wisdom, humor is considered as one of the personal qualities people admire, which may not only give comfort and build up interpersonal relationships but also help to defend oneself, amuse, criticize and even satirize others. Moreover, in the face of eternal threat it can eliminate embarrassing situations and enhance one's self-esteem and competence. In brief, the unique charm of humor has earned its good graces in human communication and social interaction. Therefore, to create and appreciate witty humor is a desirable ability that enjoys people's high praise.

Researchers from various disciplines have been working on it for centuries ranging from philosophy, literature, psychology, linguistics, sociology, anthropology to biology and medical science. Their findings have been productive and fruitful and shed significant light undoubtedly on such aspects of humor as its formation, types and genres, its essence, features and the topics associated with it. Besides, how humans create wiser humor and promote appreciation of humor is a major concern among scholars.

However, humor, as a multi-disciplinary phenomenon, is so formidable and complex that all those studies seem to have little agreement on its nature or its definition. According to Wikipedia, humor is generally regarded as the tendency of expediences to provoke laughter and provide amusement. Since scholars all define humor according to certain aspects, there is no universally acknowledged definition of humor that could satisfy them all. Hence, it is worthwhile to reconsider such an intriguing behavior.

\subsection{Studies of Humor at Home and Abroad}

It has been a long history to study humor at home and abroad. It is often investigated from a variety of perspectives of psychology, sociology and linguistics. With the flourish of theories like semantics, cultural linguistics, and pragmatics in particular, they allow us a wider vision and new perspective to do some research on humor. However, studies conducted from these perspectives are limited to some extent, there needs to make further study of humor.

Among all the linguistic studies of humor, it seemingly shows the prevailing and influential study is a semantic script theory of humor (SSTH for short) by Raskin from a semantic perspective within the framework of transformational-generative grammar, which puts emphasis on the linguistic forms of punchlines. It is believed as the first semantic theory of humor. The main hypothesis of SSTH states a text may be regarded as a humorous one if it could meet the two conditions. A text, fully or partly, is compatible with two different scripts and the two scripts in which the text is compatible are opposite (Raskin, 1985: p. 99). Based on the hypothesis, if a certain text could be humorous, it may be a must to meet these two conditions. However, it is plain that we could not apply the SSTH to account for the differences of quality in humor and thus then not distinguish a good joke from a bad one (Attardo, 1994: p. 214). Later in 1991 Attardo presents five layers of joke representation model with six knowledge resources, that is, language (LA), narrative strategy (NS), logical mechanism (LM), 
situation (SI), script opposition (SO) and target (TA). Attardo and Raskin (1991) modify the model and that is the general theory of verbal humor, so called the General Theory of Verbal Humor (GTVH for short). In Attardo's eyes, GTVH is not only a linguistic theory and but also includes other areas of linguistics as well, most remarkably, textual linguistics, the theory of narrativity, and pragmatics (Attardo, 1994: p. 222).

When cognitive pragmatics arose in the eighties of the last century, the cognitive study of language in communication has increasingly become important in the field of cognitive linguistics. Relevance: Communication and Cognition, written by Sperber and Wilson (1986), as core of cognitive pragmatics, tries to analyze the nature of communication and to illustrate the interpretation of utterance in listener's mind. It promotes the rapid growth of studies of utterance humor scientifically and systematically in terms of cognitive pragmatics. Those studies reveal that the production and interpretation of utterance humor is a process of communication in cognition. Sperber and Wilson (1998) note that people's communication is a process of pursuing relevance. With two fundamental principles, communicative principle and cognitive principle, relevance theory may make us explore the production and appreciation of utterance humor and find a good explanation from the perspectives of communication and cognition. The most influential of current cognitive theories regarding verbal joke humor is bisociaiton. In his seminal work The Act of Creation Koestler coined and defined it as the clash of two habitually incompatible frames of reference. He endeavors to draw analogies between the comic, the scientific and the poetic spheres and argues it consists in the discovery of hidden similarities (Koestler, 1964: p. 27).

Partington (2006) uses abundant examples from language corpora to examine what speakers try to achieve by producing "laughter-talk" and what listeners are signaling when they produce laughter. He focuses upon the tactical use of laughter-talk to achieve specific rhetorical and strategic effects. It is one of the first works to have recourse to a sizeable database of examples of laughter in spontaneous running talk. In his study he primarily verifies the bisociaiton with corpora and makes the conclusion that the theory is a reasonable one to explain and analyze punchlines.

Both linguistics and studies of humor have recently witnessed an emergence of interest in the research on humor in China. The linguistic study of humor could be dated back to publication of the first academic works in 1987 written by Professor Hu Fanzhu, which serves as an impetus for the growing interest in and the ensuing waves for studies of humor. His work itself makes the way for the future and further research and thus plays a milestone-1ike role.

In China, studies of humor from the perspective of relevance theory are emerging prosperously in recent years. He \& Ran (1998), as pioneers in the study of relevance theory, notice the humorous effect of intentional misinterpretation. Chen (1999) applies relevance theory to the study of the production of humor. Tu (2003) contends that humor is produced as a result of different in- 
terpretations of the mutual cognitive environment of communication. And the intensity of humorous effects mainly depends upon the contrast between the maximal relevance and the optimal relevance. Wang (2001) makes use of one of the theories of humor mechanism, brings examples to the scope of pragmatics, for analysis. He concludes that with pragmatic analysis and incongruity theory, one may dawn on how humor is elicited and interpreted. Wang and Lin (2003) probe into the mental mechanisms involved in the process of English verbal humor interpretation from the perspective of relevance theory and conceptual blending theory. They hold that the successful reading of a verbal humor is decided not only by relevance and inference, but by conceptual blending and the emergent structure. They also maintain that RT and CB supplement each other in relation to the happy understanding of verbal humor. Some researchers have tried to explore humor from other various perspectives, such as pragmatics, rhetorics, and so on. Gao Shenglin (2004) supports that humor may be categorized into rhetorics. He insists verbal humor is a rhetorical phenomenon in that the majority is demonstrated through some rhetorical ways. Li (2008) figures that verbal humor is elicited by variations of language memes in Chinese comic Dialogues (CCDs for short) and suggests the memes that produce verbal humor in CCDs trying to discover their origins from forms or meaning of proverbs, catch phrases, folk adages, verse and quoted lines. With incongruity theory of humor, the study holds the view that the linguistic memes occurring at various levels of language might contribute to the verbal humor in CCDs, which is thought to be mechanisms at work for humor. He (2003) contends bona-fide and non-bona-fide communication might be differentiated in the study of conversational principles. The non-bona-fida communication is governed by the Humor Principle instead of CP and PP, therefore the study of humor as violation of Cooperative Principle or PP maxims is not correct. The Humor Principle is the opposite of the maxims of $\mathrm{CP}$ and PP in non-bona-fide communication. He also suggests Humor Principle should be contained in pragmatics side-by-side with $\mathrm{CP}$ and $\mathrm{PP}$ as a key pragmatic principle.

Ge (2011) investigates the features of Chinese humorous texts with the General Theory of Verbal Humor as the theoretical framework and focuses on a systematic analysis of Fortress Besieged with a Chinese-English bilingual parallel corpus. Ge \& He (2012) analyze "Wei Cheng" and its English version within the same theoretical framework in order to explore how alien sources produce a humorous text in its production and interpretation, and how many patterns exist for translating alien sources in humorous texts. In general, as Wang and Lin (2011) state, with the introduction of western theories on humor in China, the researches made from a variety of disciplines are booming, whereas there are some drawbacks to be overcome in future, for example, being too dependent on the western researches and lacking in contribution to development of humor theories, etc..

The previous studies, although somewhat comprehensive, have not yet generated systematic and thus convincing theories concerning the definition, the working mechanisms of humor and its linguistic expressions as well. A un- 
animous viewpoint is still in question. Thus, it is worthwhile and significant to do some further research on it.

In contrast to the vast literature on humor, comparatively little has been done on humor from the perspective of corpus linguistics. Compared with the mentioned researches, this study takes advantage of the corpus-driven method with a large number of data objectives and real data contexts to explain humor from a perspective of phraseological theory hoping something new could be found out in order to develop and further humor theory. Previous studies about the relationship between language and humor have been classified into two camps. Roughly speaking, one is cognitive-psychological and the other is socio-anthropological. The former has focused on laughter thinking it is a signal of humor; the latter looks at laughter in its social contexts. However, in more recent times, with the development of corpus technology, allied to the increasing availability to materials in electronic form on the Web, it has allowed us to go to corpus for help and approach the study of language within the context of the scientific method (Leech, 1992). With data evidence it may bring us new ideas and bridge the gap of previous studies. In addition, because humor frequently rests on cultural concepts such as social conventions, stereotypes, and the like, the study of humor will undoubtedly deepen our understanding of social communication and enhance the explanation of pragmatic discourse.

\subsection{Theoretical Framework}

Thanks to the rapidly growing development of corpus linguistics, it becomes possible to investigate linguistic phenomena upon a large volume of data. A group of scholars, collectively referred to neo-Firthian school, work within the framework suggested by J. R. Firth and find an approach to language, among whom the most prominent supporters of the neo-Firthian approach has been John Sinclair. He was one of the first people who brought Firth's ideas together with corpus linguistics methodology.

Co-selection is foremost in Neo-Firthian corpus linguistics (Sinclair, 1991, 1996, 2004). It is involved in lexis, grammar and meaning. It gives enlightenment to a brand-new perspective and framework of language description and initiates new study fields. Sinclair proposes co-selection as a central descriptive mechanism of language in use (Stubbs, 2009). It tries to describe the interaction between word-forms as well as form and meaning in communication. By virtue of the fact, how to select word-forms is not a simply independent choice, but a choice between lemmas and word-forms, lexis and grammar.

As the core mechanism of language description in corpus linguistics, there are four aspects described in co-selection theory, that is, collocation, colligation, semantic preference and semantic prosody. Collocation demonstrates the co-selection between lexis and lexis, namely, between the node and collocates; colligation displays the co-selection between lexis and grammar, namely, between the node and structure; semantic preference presents the co-selection 
among lexis, grammar and meaning; semantic prosody reveals the co-selection among lexis, grammar and function.

With further development of Firthian contextual theory of meaning, Sinclair (1996) elaborates the descriptive categories of co-selection for an extended unit of meaning, covering the node, collocation, colligation, semantic preference and semantic prosody. In view of the fact that an extended unit of meaning is the operational model of co-selection, it integrates varied co-selection relationships and their analytical methods. The model in detail has the following components seen in Figure 1 (Stubbs, 2009: p. 125).

With such a descriptive paradigm, Sinclair presents co-selection as a central descriptive mechanism of language in use, that is to say, the notion that speakers in normal communication select features of discourse in batches (Morley \& Partington, 2009). Meaning could be represented by types of co-selection, like lexis and lexis, lexis and grammar, lexicogrammar and register or topics. It specifies the restriction of the node at the four levels within co-selection. In short, the model is the systematic and specific interpretation of co-selection thus providing a significant perspective and descriptive mechanism for corpus-driven phraseology.

Collocation is an old idea that has been defined in various ways. As for the term collocation, it was first brought into prominence in lexical research by Firth, meanwhile along with his famous elaborate depiction: "You shall know a word by the company it keeps" (Firth, 1957: p. 11). That is to denote the idea that important aspects of the meaning of a word (or another linguistic unit) are not contained within the word itself or considered in isolation, but rather subsist in the characteristic associations that the word participates in, alongside other words or structures with which it frequently co-occurs, in what Firth calls "an abstraction at the syntagmatic level" (Firth, 1957: p. 196). He also contends collocates of a certain word are descriptions of the customary items of the word (Firth, 1968: p. 181). Thus, a habitual co-occurrence of individual word-forms with mutual expectancy could be seen as the key part of collocation.

However, when moving beyond such basic generalities and attempt to pin down collocation either operationally or conceptually, we find a great multitude of different definitions. Greenbaum puts forward that collocation usually co-occurs frequently with two word-forms in language (Greenbaum, 1974: p. 82). Halliday \& Hasan, argue lexis is likely to need the only recognition of lexical items linearly co-occurred together with some measures of significant proximity, either a scale or at least a cut-off point (Halliday \& Hasan, 1976: p. 75). We could summarize that collocation illustrates the syntagmatic relation of lexical items. Cowie concurs collocation is meant to co-occur with two or more lexical items as realizations of structural elements within a given syntactic pattern (Cowie, 1981: p. 132). Hoey presents another aspect of collocation is such a lexical term that it has long been the name assigned to the relationship between word-forms appearing much greater than random probability in a certain textual context (Hoey, 1991: pp. 6-7). 


\begin{tabular}{ccc}
\hline Collocation & Tokens & Co-occurring word-forms \\
\hline Colligation & Classes & co-occurring grammatical classes \\
Semantic preference & Topics & Textual coherence \\
Semantic prosody & Motivation & Communicative purpose \\
\hline
\end{tabular}

Figure 1. Sinclairian extended unit of meaning.

Sinclair claims collocation is the occurrence of two or more word-forms within a short space of each other in a certain text (Sinclair, 1991: p. 170). Now the majority of linguists agree that the only way to reliably identify the collocates of a given word or phrase is to study patterns of co-occurrence in a text corpus. And Sinclair et al. define node and collocate as follows. A node is thought to be an item whose total pattern co-occurs with other word-forms under examination; a collocate is any one of the items which occurs with the node within a specified span (Sinclair et al., 2004: p. 10). In other words, Sinclair suggests that there are three "technical terms" in describing collocation. Research on collocation mainly stresses the collocates of a node within a span via concordancing. In corpus linguistics a concordance, namely, an index of each lexical item in a text plays a central role since it is like a reference given to the place of each occurrence. Moreover, as a set of "the occurrences of a lexical item, each one merely exists in its own contextual environment" (Sinclair, 1991: p. 32). KWIC (Key Word in Context) is the widely adopted format in data-processing for concordance, in which the word-form under examination is shown in the middle of each concordance line, and the length of the context is specified for various purposes. Stubbs deems that collocation is to describe a lexical relationship between two or more words which tend to co-occur with each other in a running discourse (Stubbs, 2001: p. 24). Wei proposes collocation is conventionally regarded as a syntagmatic realization of non-idiomatic meanings in certain texts associated with a string of word-forms co-occurring in a grammatical structure with mutual expectancy greater than chance (Wei, 2002: p. 100).

The preference of Sinclair and his colleagues for collocation-via-concordance is rather crucially linked to their theoretical stances on the nature of language and of corpus linguistics. In particular, a number of extensions to the idea of collocation which are typically identified by using the collocation-via-concordance approach-namely colligation, semantic preference and semantic prosody-have become central concepts in neo-Firthian corpus linguistics.

Colligation, still a vital concept put forward by Firth, refers to the syntactic relations in the text (Firth, 1957: p. 95). As for Lewis, he thinks that colligation is seen as the way in which a word normally co-occurs with a particular grammatical pattern (Lewis, 2000: p. 137). Mitehell contends that colligation and collocation both are the abstraction of different levels. Colligation is another form of collocational class, the syntactic relation demonstrated through word class (Mitehell, 1975: p. 83). To put it simple, it primarily indicates the grammatical relationships between word classes, instead of those specific lexical items. Colliga- 
tion could be described as the company on the grammatical level a word item keeps and the place it prefers, namely, colligations of a word will depict what it distinctively does grammatically (Hoey, 2000: p. 234). In short, colligation is a term usually reserved for the generalized classes of associations, and collocation refers to specific lexical items as particular members of colligation.

On the whole, Firth characterizes collocation as meaning-oriented recurrent word combinations with mutual expectancy. These word forms are not only grammatically but also semantically consistent. It reveals that when a word enters a new context it can be regarded as a new one. Just as Firth puts it, "the complete meaning of a word is always contextual" (Firth, 1957: p. 7). These detailed descriptions of collocation offer us a theoretical foundation for an empirical research. The study gives priority to collocation as a syntactic and semantic unit with mutual prediction. Colligation is closely intertwined with collocation, and could be seen as the collocation of a node word with a particular grammatical class of words.

In corpus linguistics semantic preference and semantic prosody are closely related but not the same. The two terms are of great significance but sometimes confusing. The following will explain them in detail. Hunston and Francis elaborate semantic preference as an abstract semantic set. They believe that a word may be said to have a particular semantic prosody if illustrated to co-occur especially with other word items which could be categorized as a particular semantic set (Hunston \& Francis, 2000: p. 137). It may be referred to a word set of normally used collocates that share semantic features (Stubbs, 2002: p. 449). The studies undertaken by Stubbs (2001), Sinclair (2004) and Partington (1998) show that lexical items co-occur distinctively with other word-forms belonging to a certain semantic set (Hunston, 1995: p. 137), and their collocates share a similar semantic feature (Sinclair, 2004: p. 142).

Semantic preference is integrated with colligation and meaning. It applies to colligation as well as to individual word-forms. Also, related collocates may have distinct semantic preferences because they belong to different word classes, for example, O'Halloran notes that "the verb form erupts in the word forms erupted or erupts has a semantic preference for human phenomenon while the noun form eruption, in the word forms eruption or eruptions, shares a preference for geological phenomena" (O'Halloran, 2007). Bublitz champions that different meanings have "different collocational patterns" (Bublitz, 1995: p. 12), and Bednarek studies short-sighted in BNC and points out semantic preference is associated with the differences between literal meaning of a word-form and its metaphorical meaning (Bednarek, 2008).

Semantic prosody is a significant aspect of word features. However, it was not until 1993 that Louw first proposed the term semantic prosody. Louw takes a contagious view and refers semantic prosody to the concordant aura of meaning where a word-form is permeated by its collocates (57). But Sinclair takes a functional view and deems that semantic prosody is attitudinal and could be seen as a continuum from semantic to pragmatic sides (Sinclair, 1996: p. 87). Therefore, 
it is easy to gain an insight into the features of semantic prosody of a certain word by its collocates. This century sees that semantic prosody has increasingly drawn attention and many studies have been conducted at home and abroad. Sinclair, as Father of semantic prosody, has enriched his experience in compilation of dictionary. He recognizes the meaning of a word is closely interrelated to the situation it employs. Besides many scholars (Louw, 1993; Stubbs, 1995; Partington, 1998; Wei, 2002, 2006), have made many a deep study of semantic prosody. Their studies demonstrate that some words tend to co-occur habitually and repeatedly with some positive, negative or neutral word items. Thus, in order to make sense in communication semantic prosody plays an indispensable role in the combination of words. It transfers not only the semantic function but the pragmatic one of a certain word, namely, it has three specific features, linguistic features, functionality and communicative purposes. The studies of semantic prosody have been made in a variety of fields, such as language teaching, second language acquisition and so on. In some context, sometimes a speaker or writer may not employ a consistent collocation to create a special effect on the listener, for instance, irony, insincerity, or humor could be interpreted as in congruity of semantic prosody (Louw, 1993: p. 173). Though the research on semantic prosody has made in different fields, studies of semantic prosody in humor are still far from enough.

Drawing on the evidence, this study will describe the normal patterns of recurrent collocates and characterize the most prominent types of co-selection in the general corpus, developed by Center for Chinese Linguistics PKU (CCL for short). With the normally expected collocation, we may discover the reasons why punchlines could be aroused and laughter may be elicited among people.

In summary, phraseology has been applied to many a study of linguistic phenomena, such as synonyms, syntactic structures, and pragmatic functions. Similarly, humor is a pragmatic phenomenon and therefore it also could be employed in the investigation of humor. Within the framework of Sinclair's co-selection theory, the study intends to explore how skit-humor comes into being, how mechanisms work for humor and how they are elicited and realized linguistically.

\section{The Present Research}

\subsection{Methods}

The research into skit-humor is an instance of a project in the nascent interdisciplinary field of corpus-driven studies. In the study, quantitative and qualitative approaches were combined with the analysis and explanation of the data collected.

This arose from the realization that some of the methodology and instruments commonly used in corpus linguistics may be adopted for the study of features of discourse (see especially Louw, 1993; Stubbs, 1996, 2001; Partington, 2004). That is to say, it was possible to combine the quantitative types of analysis used in 
corpus linguistics, which usually takes into account large quantities of texts and subjects them to statistical analysis, with the qualitative methods examining single text in detail. Corpus-driven methodology is adopted in the study, mainly including data collection and corpus compilation, data organization and corpus interrogation. Data collection performs a vital role in the research. After careful check and annotation, all the punchlines are figured out based on the audio-visual information regarding both the kinesics of performers and the contexts in which episodes occur. Then they were annotated with the information of where laughter occurs.

In the study, the author manually checked the punchlines where laughter occurs due to linguistic factors, removing those disturbing ones where laughter may be elicited because of paralinguistic reasons, and body language for example. In particular, looking into the skit-humor, the punchlines in the collected skits are analyzed to find the node and are retrieved and parsed in the general corpus developed by Center for Chinese Linguistics PKU (CCL for short). In addition, as Partington (2006) puts forward, it is not possible to know or to prove what is normal and only against a known background of what is normal and expected can we detect the unusual and meaningful usages. Thus, the general corpus, maybe called CCL corpus on the Web, was consulted and used as a reference corpus against which results are compared. For every node 100 concordances are selected randomly. The general corpus is a Chinese corpus with 787,938,678 Chinese characters developed by Center for Chinese Linguistics PKU, covering periodicals, newspapers, essays, academic books, etc.. Consequently it is of great significance to find out the normal collocation, which could attribute to the explanation of the working mechanism for the elicited humor. In the end, explanation and evaluation of the punchlines is a manual task. A major focus of the research is on the explanation of the punchlines and why they could produce laughter in the skits.

\subsection{Research Objects}

Skits have enjoyed a widespread reputation and gained incomparable popularity among the masses throughout the country. To explore skit-humor, the author chose the typical skits performed at the Spring Festival Gala via China Central Television (CCTV) from 2000 to 2011. These skits on the CCTV Spring Festival Gala have been seen as classics or in other words representative of Chinese humor. The collected skits have won "My Favorite Program of the Gala" award through the audience's votes performed on the Spring Festival Gala, which is regarded as the most popular nationwide gala in China largely dominated with the most influential celebrities' selected performances. They seemed as the peak of the television program because afterwards there weren't voting activities after the Spring Festival Gala and seemed language programs were not so popular.

Skit-humor, to some extent, as a kind of typical humor in China, has been universally accepted by Chinese audience. In appreciation of the performances, 
people will elicit laughter and enjoy themselves. By no means are laughter and humor coterminous, however, from our intuition, experience and past literature we can know they are closely related. Skit has gained great publicity among the Chinese audience. It has won the enduring reputation and humor in the skit has become the often imitated and appreciated role models among common people. In other words, skit can be regarded as a representative form for humor in Chinese.

In the skits, almost each line is full of humorous utterance that elicits laughter making the performance entertaining and relaxing. Hence, the performance is always welcome among audience with their heartfelt laughter and claps. And the humorous utterances in the performance have been rooted into the Chinese culture and spread out. A bout of laughter that live audience elicits at the Gala illustrates one of the most noticeable characteristics of the skits, the masterly use of humor.

In order to examine skit-humor, the author examined the punchlines occurring in the skits and established one database by downloading the transcripts one by one from the CCTV website. This database comprises 12 skits or about 11,720 Chinese characters. The transcripts contain indications of where laughter occurs-the character "xiao4 (笑)" in round brackets and some illustrations of where the scene happens, for instance, the description of the performers' actions.

\subsection{Research Questions}

The research questions to be answered in the current study are as follows:

1) What are the categories of skit-humor distributed in the skits?

2) What are phraseological features of the verbal humor in the skit-humor?

3) What are the reasons responsible for or mechanisms at work in the verbal humor?

\subsection{Results and Discussion}

The analysis was conducted and found all the punchlines were examined manually and the humor could be broadly grouped into two types: one is called verbal humor, referring to the humor expressed or conveyed by means of a linguistic system (Ritchie, 2004). Verbal humor, a sort of utterance humor, lively and interesting, basically conveys information and communicative intention with a variety of linguistic properties. The other type is termed as nonverbal humor, or scene humor, referring to a humorous situation that is not created or expressed by language. In the skits, it specifically refers to the humor produced mainly by the body languages of the performers in the skits, for example, their interaction and communication through actions, the facial expressions they wear, eye contact, comic costumes, the situation where the performers in the skit are involved and the stage properties, etc.. According to the classification of the study, Table 1 could show the distribution of total punchlines and the punchlines resulting from linguistic and paralinguistic factors respectively in the following. 
Table 1. Distribution of Skit-humor in the Skits (2000-2011).

\begin{tabular}{ccccccc}
\hline \multirow{2}{*}{ Year } & Name of the skit & \multicolumn{2}{c}{ Verbal humor } & \multicolumn{2}{c}{ Nonverbal humor } & \multirow{2}{*}{ Total } \\
\cline { 3 - 6 } & & Frequency & Percentage & Frequency & Percentage & \\
\hline 2000 & Zhong1dian3gong1 & 38 & $79.2 \%$ & 10 & $20.8 \%$ & 48 \\
2001 & Mai4guai3 & 29 & $78.4 \%$ & 8 & $21.6 \%$ & 37 \\
2002 & Mai4che1 & 44 & $75.9 \%$ & 14 & $24.1 \%$ & 58 \\
2003 & Xin1bing4 & 23 & $47.9 \%$ & 25 & $52.1 \%$ & 48 \\
2004 & Song4shui3gong1 & 42 & $66.7 \%$ & 21 & $33.3 \%$ & 63 \\
2005 & Gong1fu1 & 36 & $61 \%$ & 23 & $39 \%$ & 59 \\
2006 & Shuo1shi4er0 & 54 & $70.1 \%$ & 23 & $29.9 \%$ & 77 \\
2007 & Ce4hua4 & 35 & $61.4 \%$ & 22 & $38.6 \%$ & 57 \\
2008 & Huo3ju4shou3 & 68 & $85 \%$ & 12 & $15 \%$ & 80 \\
2009 & Bu2cha4qian2 & 74 & $84.1 \%$ & 14 & $15.9 \%$ & 88 \\
2010 & Juan1zhu4 & 66 & $77.6 \%$ & 19 & $22.4 \%$ & 85 \\
2011 & Tong2zhuo1de1ni3 & 60 & $83.3 \%$ & 12 & $16.7 \%$ & 72 \\
Total & & 569 & $73.7 \%$ & 203 & $26.3 \%$ & 772 \\
\hline
\end{tabular}

From the above table, it is noticeable that all the punchlines in the skits are examined and broadly classified into two categories. One is verbal humor and the other is so-called nonverbal humor. When it comes to verbal humor in the skits, it can be seen that the humor elicited is closely related to language itself, yet nonverbal humor in the skits refers to those punchlines which are produced beyond words.

The total number of punchlines occurring in the skits amounts to 772. Punchlines resulting from paralinguistic factors add up to 203, whilst those due to linguistic factors come to 569. Thus, the number of verbal humor accounts for the majority, say, $73.7 \%$ of the total. By examining the percentage of the punchlines, almost in every skit the percentage of verbal humor is much higher than that of nonverbal humor, for instance, in the year 2000, all the punchlines for verbal humor account for $79.2 \%$, whereas $20.8 \%$ for nonverbal humor. If carefully observed, the table also reveals that for each skit, verbal humor overwhelmingly takes an advantage over nonverbal humor, except the year of 2003, but there seems little difference between the two proportions. On the other hand, we may conclude that the skits thrive on the use of language with intention to create humor, though in some cases, humor could be yielded by non-verbal stimuli as well, that is, without any resort to language. Thus, then, to a certain extent it is of great significance to study verbal humor.

In summary, verbal humor which is the major concern in skit-humor is illustrated in particular within the analytical framework of co-selection, in which the phraseological features are tried to be explored. It will analyze the punchlines selected from the skits where collocates of the node are unusual based on the 
evidence from CCL corpus.

First of all, verbal humor in the skit-humor is produced essentially due to unusual lexical collocations. Let us examine the following three examples from the skits from the perspective of lexical collocation.

For example: 1) a) ... zhang3de0 ting 3 wei3wan3 de0, shi4ba0? (长得挺委婉 的, 是吧? )

To group these collocates according to semantic features which they belong to, a brief interpretation is given based on the collocates listed to present a general picture of the companions “zhang3de0 (长得)" usually keeps. Observing its right collocates in contexts, we find the concordance lines show the collocational behaviors reveal recurrent semantic groups, rather than the individual words. Among the 100 citations examined at random, 59\% of the collocates are used to describe the appearance, shape, figure, or organs of people and animals and 22\% of them is to depict plant's or vegetable's growth. Both of the two semantic features accounting for the majority, $81 \%$ of the total, are commonly used collocates of the node “zhang3de0 (长得)", whereas the semantic features of raising a question and comparison are the minority.

From the observation of citations of “wei3wan3 (委婉)", a number of habitual collocations are set up, and plainly “wei3wan3 (委婉)” is followed by nominals like “shuo1fa3 (说法)”, “pian1zhang1 (篇章)”, “yuan2ze2 (原则)”, “ci2yu2 (词 语)”, “hua4yu2 (话语)”, etc.. And also there are verb collocates as “bian4de0 (变 得)”, “xiang1shang1 (相商)” and so forth. The right collocates of “zhang3de0 (长 得)” always co-occur with words like “hao3 (好)”, “xiong2zhuang4 (雄壮)”, etc., therefore we may conclude that “zhang3de0 (长得)" has a preference for describing the appearance of people, animals and plants. Similarly, the data of “wei3wan3 (委婉)” show that it has a preference of people's talk or the way people communicate with others. So we find that there is no intersection between them. It follows that there's a semantic clash between “zhang3de0 (长得)" and “wei3wan3 (委婉)”.

And another instance is also alike. Consider, for example, the following line from the skits.

2) a) Cong1ming2de0 zhi4shang1 you4 zhan4ling3 gao1di4 le0. (聪明的智商 又占领高地了 ...)

We analyze this verbal humor by concordancing the two nodes, "zhi4shang1 (智商)” and “zhan4ling3gao1di4 (占领高地)”. The concordance lines show that the node "zhi4shang1 (智商)" in Chinese has recurrent collocates such words as “qing2gan3 (情感)”, “xin1ling2 (心灵)”, “gao1 (高)”, “bu4gao1 (不高)”, etc.. Besides, there exist the verbal collocates, like “wan2 (玩)”, “qu3jue2 (取决)”, etc.. Then analyzing its semantic preference we could see that the node has such a semantic preference as an indication of "high, low or average" like "gaol (高)" and “cha4 (差)" and as the categories of intelligence like "qing2gan3 (情感)" and “xin1ling2 (心灵)”. Five concordance lines of “zhan4ling2 gao1di4 (占领高地)” are spotted in CCL corpus in total. In contrast, the semantic preference of 
“zhan4ling2 gao1di4 (占领高地)” is to describe the military strategy or movement, which is quite different from those of “zhi4shang1 (智商)". Therefore, we could conclude that when “zhi4shang1 (智商)" co-occurs with “zhan4ling3gao1di4 (占领高 地)", there is a clash in semantic meaning, which is the very part where people laugh at. When the two unusual collocates co-occur, listeners may get surprised and feel novel thus laughter is produced.

Then look at another instance from the skits. For instance:

3) a) ... Ni3 you3 zhe4me0da4 er2zi0, chu2fei1 ti2qian2 yong4 da4peng2 kou4zhu4le0. (你有这么大儿子，除非提前用大棚扣住了。)

The latter part of this line is particularly interesting, as illustrated by the concordance lines for “da4peng2 (大棚)” drawn from the 581,794,456 Chinese characters of modern Chinese corpus at CCL corpus. Randomly everyone is reproduced here. If we study the collocates to the left or right of “da4peng2 (大棚)”, we find that the concordance lines show “da4pen2 (大棚)" has a preference with collocates for describing its texture or the place where vegetables grow. From the contexts of the concordance lines we see that the habitual collocates of “da4peng2 (大棚)” are non-animated, like “cai4/shulcai4 (菜/蔬菜)”, while “er2zi0 (儿子)” is animated, referring to a male human offspring. Two phrases, “er2zi0 (儿子)” and “da4peng2 (大棚)” occurring simultaneously elicit laughter.

The correlation between repeatable aspects of text process and repeatable events outside the text is far more striking than what people's intuition could ever have predicted. It must be verifiable as a piece of text process in our experience of the whole language. In more than two fifths of the following concordance lines from the 581 million word corpus, “da4peng2 (大棚)” is followed by words like “su4liao4 (塑料)”, “shu1cai4 (蔬菜)”, “wen1shi4 (温室)”, “shou1ru4 (收入)”, and “zhong4zhi2 (种植)". The proportion of these collocates could be further verified from the corpus. In it the node “da4peng2 (大棚)” appears 2146 times and corroborates the profile which emerges from the concordances.

Next, from the phonological collocation, it could be noted that the reversal may contribute to the verbal humor in the skits when the node word reverses its word order. Now take three instances for example from the skits and then a detailed description of this reversal will be illustrated in the following. For example:

4) a) Da4ma0 dou1 you3 zi4ge4de0 bo2ke4 la0? b) Ming2ren2ma0, dou1 ke4bo2...

(大妈都有自个的博客啦? 名人嘛, 都刻薄。)

In the punchline these two node words, “bo2ke4 (博客)" and “ke4bo2 (刻 薄)”, co-occur with each other. “bo2ke4 (博客)” has a semantic preference for means of marketing and media for people to communicate, with such verb collocates as “xie3 (写)" and “li4yong4 (利用)”. Differently the node “ke4bo2 (刻 薄)” usually collocates with words describing people’s quality and ways of doing things characterized with meanness. In this punchline, “bo2ke4 (博客)” and “ke4bo2 (刻薄)", although different in Chinese characters, the two nodes 
co-occur accidentally when the two reverse their own phonological order in Chinese and make humor elicited. We may note that all the nodes reverse its order contributes to the punchlines in the skits.

Another punchline extracted from the skits is as follows:

5) a) Han3 mai4. (喊卖。) b) Mai4 a0! Ma4i! (卖啊! 卖) a) Mai4 sha2 ya1? (卖 啥呀? )

b) Guai3 (拐 ...) a) Lian2shang4. (连上。) b) Guai2mai4 le0 a4! Guai2mai4 le0 ai4! (拐卖了啊! 拐卖了哎!)

It is shown that the collocates of "guai3mai4 (拐卖)" and it is plain to see it has a semantic preference for describing the illegal issue about women or children trafficking. In contrast, collocates of "mai4guai3 (卖拐)" are such phrases like “zhao4ben3shan1 (赵本山)" and “xiaopin (小品)”, which elaborates the skit content. These two nodes co-occur together with the same Chinese characters but the reversed word order, which makes them have different colligations. However, it is the right part of the reversed phonological order that makes all the listeners laugh.

Take another example as listed below. First, look at the concordance lines of the nodes in the punchline.

6) a) Qiao2qiao0 wo3 zhe4 ren2qi4 (燋燋我这人气。)

b) Ni3 na4 jiu4shi4 qi4ren2 (你那就是气人!)

In the citation, “qi4ren2 (气人)" and "ren2qi4 (人气)" have different colligations and recurrent collocations respectively. In Chinese, "qi4ren2 (气人)" mainly serves as an adjective with a semantic preference for making people irritated by doing or saying something while "ren2qi4 (人气)" functions as a noun with the meaning of popularity of human beings or stuff. The two phases reverse their word order in Chinese and co-occur with each other, which produces humor.

Therefore the phonological reverse collocation, on the other hand, could be included as a special form of semantic collocation by nature because after all, phonological meaning could be reflected in the semantic meaning.

Third, let us now turn to consider semantic prosody of some verbal humor in the skits. The verbal humor cited below attributes to opposite semantic prosody of each node. Here are three instances, still from the skits.

7) a) Xing4fu2 shi4 shen2me0? Da2: Xing4fu2 jiu4shi4 zao1zui4.

(幸福是什么? 答: 幸福就是遭罪。)

This instance is particularly intriguing, as is illustrated by the concordance lines of “xing4fu2 (幸福)" and “zao1zui4 (遭罪)" drawn from CCL corpus. The concordance lines show that "zaolzui4 (遭罪)" has an overwhelming "bad" prosody. Indeed the bad ones of “zaolzui4 (遭罪)” would be easy to establish and would be bound to have its own unique profile. If one applies to the knowledge to "xing4fu2 (幸福)", one discerns at once that it must follow collocates with contagion of good semantic prosody. However, the listener was keenly aware of the existence of a bad semantic prosody on “zaolzui4 (遭罪)" 
“zaolzui4 (遭罪)" in the concordance lines allows the cumulative force of the bad prosody, in all its unpleasant variety, to be accumulated from our prior knowledge as listeners.

8) a) Su2hua4shuo1 yi2ge4 cheng2gong1de0 nan2ren2 hou4bei4 bei1 yi2ge4 duo1shi4de0 nv3ren2 (俗话说一个成功的男人后背背一个多事的女人。)

First of all, let us see the concordance lines of "cheng2gong1de0nan2ren2bei4hou4 (成功的男人背后)” and “duolshi4de0 (多事的)" in CCL Corpus. In Chinese, we've got the idiom as cheng2gong1de0nan2ren2bei4hou4 (成功的男人背后) instead of cheng2gong1de0nan2ren2hou4 bei4 (成功的男人后背). So we concordance the collocates to the right of "cheng2gong1de0nan2ren2bei4hou4 (成 功的男人背后)", we could note the concordance lines show that it has a "good" prosody and offers happy associations with women such as "jian1qiang2 (坚 强)”, “wei3da4 (伟大)”, “feng4xian4 (奉献)”, “xian2hui4 (贤惠)” etc.. It has a semantic preference for a highly good praise of the woman who has devoted her life to the successful man. As for concordance lines of "duo1shi4de0 (多事的)", conversely it has an overwhelmingly "bad" prosody and unpleasant curses. The two opposite semantic prosodies co-occur with each other and produce a punchline for the listeners.

Let us see another punchline from the skits.

9) a) Ni3 da4ma1 yi3jing1 bu2shi4 ni3 liu6nian2qian2de0 da4ma1 le0, ni3 da4ye0 yong3yuan 3 shi 4 ni3 da4ye 0 ... (你大妈已经不是你六年前的大妈了, 你 大爷永远是你大爷。)

Carefully examining the concordance lines, we demonstrate in the following the random citations. It is discovered that the two node words are the same with Chinese characters but different tones in Pinyin even with more than one semantic preference. Most of the concordances show that the previous node "da4ye0 (大爷)" has the semantic preference of the respected address of elderly men and has a neutral semantic prosody. The entries for "da4ye2 (大爷)" in CCL corpus deserve comment. It is plain to note that the overwhelming evidence of a negative prosody in these instances, with its semantic preference of cursing and the self arrogant address of male. In all, the opposite semantic prosodies made by “da4ye2 (大爷)” and “da4ye0 (大爷)” produce laughter.

Fourth, some citations from the skits will be analyzed, among which the punchlines are attributed to the semantic clash not by the node itself but the context where it is located. It is the very part of co-occurrence of a certain context and lexical items that make people laugh. For example:

10) a) Yan3jing1 you3dian3 hua1, shi4ba0? b) ng4, ling2xia4hao3ji3du4. (眼睛 有点花, 是吧? 嗯, 零下好几度。)

From the concordance lines of “yan3jing1hual (眼睛花)", they illustrate that the left collocates of the node is the exhausted or the elderly. However, from the data, "ling2xia4hao3ji3du4 (零下好几度)" has a strong preference of describing the temperature of the cold weather in that it is followed by "dilwen1 (低温)". “yan3jing1 (眼睛)” in Chinese can collocate with “du4 (度)”, a certain degree, which makes it impossible to collocate with "ling2xia4hao3ji3du4 (零下好几度)" 
as a convention or rule. The contrasting collocation is unconventional and makes people laugh.

Also, there is another instance like:

11) a) Zhe 4 xiao2shenglyin 1 ting 3 tian2de0, han2tang2liang 4 ting2gaola0, zui4qi3ma3 si4ge4jia1hao4. (这小声音挺甜的, 含糖量挺高啊, 最起码四个加 号。)

Drawn from CCL, there are 3 citations altogether. “si4ge0 jialhao4 (四个加 号)” is preceded by “bing4 (病)”, “tang2niao4bing4 (糖尿病)” and “xue3tang2 (血糖)”. In this line, “sheng1yin1tian2 (声音甜)” co-occurs with “si4ge0jia1hao4 (四个加号)” and the collocational combination is very confusing and surprising.

Look at a third example illustrated in the skits.

12) a) Wo3 shuo1 shen 2 me0jiu3 zhe 4 me0 gui4, ta1 shuo1 zhe4shi4 ren2tou2ma3mian4 (我说什么酒这么贵, 她说这是人头马面...)

From the above figures we may see the recurrent collocates of "ren2tou2ma3 (人头马)” are “jiu3 (酒)” and the stuff associated with wine. It has the semantic preference of the brand or company of alcoholic drink, prices of the spirits, etc.. However, it is plain to see that “ren2tou2ma3mian4 (人头马面)" refers to the really existing things. The node “ren2tou2ma3mian4 (人头马面)” and “jiu3 (酒)" co-occur with each other in a context, which makes people feel funny and then burst into a laughter.

In short, the above deals with the explanation and description of phraseological features of the punchlines extracted from the skits. From all the illustrations, we may conclude that there are five aspects of verbal humor we examined the punchlines from, namely, collocational clashes including semantic clash and phonological clash, prosody clash, contextual clash.

In the following, through the mentioned examples it will demonstrate the mechanisms at work in verbal humor and center on how precisely they function and how they are realized linguistically.

As Hoey points out "when a choice of one priming is overwhelmed by another, more dominant priming [the result] is either ambiguity or humor" (Hoey, 2005: p. 170). A lack of prosody may contribute to the apparent unusualness of an utterance because priming prosody contributes to the apparent naturalness of an utterance. Consequently speakers could consciously override the normal combinatorial primings or priming prosody of a phrase for special effect, namely, that which Partington has termed "unusuality" (Partington, 1998: pp. 121-143).

Also in phraseology Sinclair points out "the open-choice principle and the idiom principle are the linguistic correlates because complete freedom of choice of a single word is rare and so is complete determination" (Sinclair, 2004: p. 29). The principle of idiom means that "the language user has available to him a large number of preconstructed or semi-constructed phrases that constitute single choices, even though they appear to be analyzable into segments" (Sinclair, 1991: p. 110). Comparably, he also proposes the open-choice principle as a secondary 
model. It may not be relinquished, because a text still has many switch points where the open choice model will come onto play. It has an abstract relevance, in the sense that much of the text shows a potential for being analyzed as the result of open choices, but the other principle, the idiom principle, dominates (ibid.: 114). The open choice principle shows the tendency for a word which has a fixed meaning in reference to the world, thus anyone who wants to name its referent would have little option but to follow it, especially if the relationship works in both directions, while the idiom principle demonstrates words tend to go together and make meanings by their combinations. So we may conclude that the two principles explain the way how people interpret texts or talks and the idiom principle dominates the interpretation of communication.

Sinclair proposes the idiom of phraseological principle of language, default mode of interpreting discourse but if it fails to explain the text, listeners retain the option of applying the open-choice principle. The process may be called relexicalization, namely, the "freeing up" of the parts of a normally frozen, preconstructed lexical unit (Partington, 2006: p. 119).

One mechanism of humor is to upset the normal collocational behaviors. For instance, in Example (1) where the collocation of “zhang3de0 (长得)" is transformed into “wei3wan3 (委婉)", but how can the performer be sure this will be the listener's favored first reading? The answer, of course, is that "zhang3de0 (长 得)” has a semantic preference for the semantic set of expressions indicating human beings, animals, or plants. Nonetheless the semantic preference for “wei3wan3 (委婉)” is abstract and non-animated nominals. In most cases it is the collocate immediately to the right of “zhang3de0 (长得)" that signals that humor may be intended. Then, they may be forced to reinterprete the normally preconstructed phrases and resort to a humorous reading to understand the unusual collocation.

Next then, in Example (5) because of the phonological reverse collocation of “guai3mai4 (拐卖)" and “mai4guai3 (卖拐)" the contextual aspect of the text forces a sound sequence to be reinterpreted grammatically (syntactically or morphologically). As lexical priming theory says, the normal priming prosody that the sound sequences may be interpreted as a unit and therefore overridden. So the effect is achieved by a general revitalization of the language at the point of the text.

Last let us suggest another prosody in citation (7). First of all, since the priming prosody is played at the level of semantic preference, the concordance lines of “xing4fu2 (幸福)” display a semantic preference which occurs with expressions with good semantic prosody. But the concordance of “zaolzui4 (遭罪)" has a highly unfavorable semantic prosody, that is to say, it shows a very marked tendency to co-occur with highly unpleasant entities. Hoey stresses normal priming prosodies could always be overridden by users, thus, then, creativity with language is largely a process of overriding or exploiting normal primings where humor may be elicited in such a process (Hoey, 2005: p. 155). All in all, 
examples of this kind start to help us in determining criteria for recognizing semantic prosodies. One interesting and effective type of semantic prosody clash is, whereby something which is normally expected to be appraised as good or bad suddenly co-occurs with the opposite.

In a word, relexicalization is one of the fundamental linguistic processes. Partington champions if "salient" reading fails to interpret the text satisfactorily, the listener will resort to the open choice mode to reinterpret the semi-constructed phrase (Partington, 2006: p. 120). Of course, neither of the "straight" primings, the default collocational reading is funny. The listener knows these texts are meant as jokes and begins a backtrack to find a humorous reading. So we could note that people violate the idiom principle in the process of interpreting humor.

\section{Conclusion}

With the detailed discussion and analysis, the following findings could be concluded. The categories of skit-humor or punchlines in the collected skits could be roughly classified into nonverbal humor and verbal humor. Of all the forms of humor, they are mostly obvious based upon the creative use of language, and the most clearly dependent on a form of wording, which is why so many researchers have chosen to constitute a proper object of linguistic study. According to the statistics, we may summarize that verbal humor accounts for the majority of the skit-humor or punchlines in the skits. The punchlines are produced in terms of linguistic factors. While nonverbal humor, which also could be called the scene humor, refers to the punchlines made in terms of paralinguistic factors in particular performers' body languages in the skits, facial expressions, actions, the interaction of the performers, etc. Second, so as to examine verbal humor in the skits, the punchlines analyzed and channeled into five aspects in the study within the framework of co-selection, that is to say, lexical collocation, phonological collocation, semantic prosody, contextual collocation, and co-occurrence. Through careful and close analysis of the selected verbal humor, it is believed that semantic clash is the primary factor for the punchlines which may elicit laughter.

When it comes to the reasons why verbal humor could produce laughter, the study offers a linguistic account of the working mechanisms. From the observation and examination of the punchlines, it lends strong evidence not only for the psychological reality of linguistic schemata but for the argument that the default principle in interpreting normal communication is the idiomatic or phraseological mode. Relexicalization is one of the fundamental linguistic processes in appreciating humor and offers the basis of a powerful and elegant explanatory hypostudy. It describes how humor depends upon the interplay of the phraseological and the open-choice language principles, the sudden shift from the first to the second.

This study, to a great extent, although it is tentative and exploratory, will undoubtedly add persuasion and objectivity to the research on humor and in turn perfect corpus linguistics in a way thanks to the data-driven approach interacted 
with the study of humor. With large data examined, it is of great help to promote the development of humor theory and its research.

Studying humor has been an intriguing and confusing issue due to the continuous emergence of various insightful linguistic theories. Despite numerous research made on skit-humor, very little concern has been given to phraseology. Although skit-humor has drawn much academic attention, there still seems to be lacking in an objective study with a new perspective of corpus linguistics. In this study, we explored and displayed a new research, corpus-driven approach to provide an explanation for instances of language use.

First and foremost, studying humor from a perspective of corpus linguistics adds some objectivity and persuasive power. Besides, the study has both theoretical significance and practical implications. Theoretically, it proves that co-selection, based on this conducted study, may provide an effective comprehension of verbal humor in corpus linguistics. By the analysis, the study points out that the verbal humor in the skits could be attributed to semantic clash. So corpus linguistics interacting with humor study will definitely promote the development and the perfection of corpus linguistics in some way. Also with large data examined, it is of great help to promote the development of humor theory and its research. Practically, The study of skit-humor undoubtedly sheds light on verification of phraseological model in some way and encourages the use of humor, thus then, deepen our understanding of social communication, enhance the explanation of pragmatic discourse and promote foreign language teaching and research as well.

To some extent this study is tentative and exploratory and some limitations inevitably exist. In the study, humor in the skits is not spontaneous but well-designed scripts there may exist some canned laughter. In short, although we have made efforts to be as objective and prudent as possible, the study still leaves a lot of space for future research to explore. It is hoped, however, that this study could serve as a guide at least, for further data-driven studies of humor.

\section{Acknowledgements}

The study is part of the research results of Higher Education Institutes Philosophy \& Social Science Research Project: A Corpus-driven Study of Chinese Humor (Grant No. 2017SJB1755) as well as Basic \& Applied Basic Research Project: A Study of Skit-Humor within the Framework of Co-selection (Grant No. KYY15509).

\section{Conflicts of Interest}

The author declares no conflicts of interest regarding the publication of this paper.

\section{References}

Attardo, S. (1994). Linguistic Theories of Humour. Berlin: Mouton de Gruyter.

Attardo, S., \& Raskin, V. (1991). Script Theory Revisited: Joke Similarity and Joke Repre- 
sentation Model. Humor: International Journal of Humor Research, 4, 293-347. https://doi.org/10.1515/humr.1991.4.3-4.293

Bednarek, M. (2008). Semantic Preference and Semantic Prosody Re-Examined. Corpus Linguistic and Linguistic Theory, 4, 119-139. https://doi.org/10.1515/CLLT.2008.006

Bublitz, W. (1995). Semantic Prosody and Cohesive Company: Somewhat Predictable. In General and Theoretical Papers (pp. 1-23). Duisburg: L.A.U.D. Linguistic Agency University of Duisburg.

Chen, C. H. (1999). Analysis of Conversation Humor from the Perspective of Relevance Theory. Journal of PLA Foreign Languages University, 1, 21-24.

Cowie, A. (1981). The Treatment of Collocations and Idioms in Learner's Dictionaries. Applied Linguistics, 2, 223-235. https://doi.org/10.1093/applin/2.3.223

Firth, J. (1957). Papers in Linguistic. Oxford: Oxford University Press.

Firth, J. (1968). A Synopsis of Linguistic Theory 1930-1955. In B. Dodd (Ed.), Selected Papers of J. R. Firth 1952-59 (pp. 1-39). Birmingham: University of Birmingham Press.

Gao, S. L. (2004). The Definition of Humor and Its Categorization of Subject Family. Seeking Truth, 5, 100-104.

Ge, L. L. (2011). On the Patterns for Translating Alien Sources in Humorous Texts-A Study Based on a Chinese-English Bilingual Parallel Corpus. Foreign Language Research, 1, 117-122.

Ge, L. L., \& He, Y. J. (2012). On the Features of Chinese Humorous Texts Based on the General Theory of Verbal Humor. Journal of Foreign Languages, 4, 35-44.

Greenbaum, S. (1974). Some Verb-Intensifier Collocations in American and British English. American Speech, 49, 79-89. https://doi.org/10.2307/3087920

Halliday, M., \& Hasan, R. (1976). Cohesion in English. London: Longman Group Limited.

He, W. Z. (2003). Analysis of Humor Principle in Conversation. Foreign Language Education, 4, 11-16.

He, Z. R., \& Ran, Y. P. (1998). A Review of Relevance Theory the Essentials of Cognitive Pragmatics. Modern Foreign Languages, 3, 93-107.

Hoey, M. (1991). Pattern of Lexis in Text. Oxford: Oxford University Press.

Hoey, M. (2000). A World beyond Collocation: New Perspectives on Vocabulary Teaching. In M. Lewis (Ed.), Teaching Collocation (pp. 224-225). Hove: Language Teaching Publications.

Hoey, M. (2005). Lexical Priming. London: Routledge.

Hu, F. C. (1987). Linguistics of Humor. Shanghai: Shanghai Academy of Social Sciences Press.

Hunston, S. (1995). A Corpus Study of Some English Verbs of Attribution. Functions of Language, 2, 133-158. https://doi.org/10.1075/fol.2.2.02hun

Hunston, S., \& Francis, G. (2000). Pattern Grammar. Amsterdam, Philadelphia, PA: John Benjamins. https://doi.org/10.1075/scl.4

Koestler, A. (1964). The Act of Creation. London: Hutchinson.

Leech, G. (1992). Corpora and Theories of Linguistic Performance. In J. Startvik (Ed.), Directions in Corpus Linguistics (pp. 105-122). Berlin: Mouton de Gruyter.

Lewis, M. (2000). Teaching Collocation. Hove: Language Teaching Publications.

Li, J. (2008). Memetics and Verbal Humor. Foreign Language Research, 1, 74-78.

Louw, B. (1993). Irony in the Text or in Sincerity in the Winter? The Diagnostic Potential 
of Semantic Prosodies. In M. Baker, G. Francis, \& T. Bonelli (Eds.), Text and Technology: In Honor of John Sinclair (pp. 157-176). Amsterdam: John Benjamins. https://doi.org/10.1075/z.64.11lou

Mitehell, T. F. (1975). Principles of Firthian Linguistics. London: Longman.

Morley, J., \& Partington, A. (2009). A Few Frequently Asked Questions about Semantic-or Evaluative-Prosody. International Journal of Corpus Linguistics, 14, 139-158. https://doi.org/10.1075/ijcl.14.2.01mor

O’Halloran, K. A. (2007). Critical Discourse Analysis and the Corpus-Informed Interpretation of Metaphor at the Register Level. Applied Linguistics, 28, 1-24. https://doi.org/10.1093/applin/aml046

Partington, A. (1998). Patterns and Meanings. Amsterdam, Philadelphia, PA: Benjamins. https://doi.org/10.1075/scl.2

Partington, A. (2004). Utterly Content in Each Other's Company: Semantic Prosody and Semantic Preference. International Journal of Corpus Linguistics, 9, 131-156. https://doi.org/10.1075/ijcl.9.1.07par

Partington, A. (2006). The Linguistics of Laughter: A Corpus-Assisted Study of Laughter-Talk. London \& New York: Routledge. https://doi.org/10.4324/9780203966570

Raskin, V. (1985). Semantic Mechanisms of Humor. Dordrecht, Boston, MA, Lancaster: D. Reidel.

Ritchie, G. (2004). The Linguistic Analysis of Jokes. London: Routledge.

Sinclair, J. (1991). Corpus Concordance Collocation. London: Oxford University Press.

Sinclair, J. (1996). The Search for Units of Meaning. Textus, 9, 75-106.

Sinclair, J. (2004). Trust the Text: Language, Corpus, and Discourse. London: Routledge.

Sinclair, J. et al. (2004). English Collocation Studies: The OSTI Report. London: Continuum.

Sperber, D., \& Wilson, D. (1998). Irony and Relevance: A Reply to Drs. Seto, Hamamoto and Yamanashi. In R. Carston, \& S. Uchida (Eds.), Relevance Theory: Applications and Implications (pp. 283-293). Amsterdam, Philadelphia, PA: John Benjamins. https://doi.org/10.1075/pbns.37.16spe

Sperber, D., \& Wilson, D. (1986). Relevance: Communication and Cognition. Oxford: Blackwell Publishers Ltd.

Stubbs, M. (1995). Collocations and Semantic Profiles: On the Cause of the Trouble with Quantitative Methods. Function of Language, 2, 1-33. https://doi.org/10.1075/fol.2.1.03stu

Stubbs, M. (1996). Text and Corpus Analysis. Oxford: Blackwell Publisher Ltd.

Stubbs, M. (2001). Words and Phrases: Corpus Studies of Lexical Semantics. New York: Blackwell.

Stubbs, M. (2002). Two Quantitative Methods of Studying Phraseology in English. International Journal of Corpus Linguistics, 7, 215-244. https://doi.org/10.1075/ijcl.7.2.04stu

Stubbs, M. (2009). The Search for Units of Meaning: Sinclair on Empirical Semantics. Applied Linguistics, 30, 115-137. https://doi.org/10.1093/applin/amn052

Tu, J. (2003). A Relevance Theoretic Account of Humor. Journal of Sichuan International Studies University, 5, 92-94.

Wang, W. B., \& Lin, B. (2003). English Verbal Humour: A Cognitive Pragmatic Inquiry. Journal of Foreign Languages, 4, 32-38. 
Wang, X. J., \& Lin, S. (2011). Reflections on a Decade of Humor Researches in China: 2001-2010. Foreign Languages Research, 5, 28-33.

Wang, Y. (2001). Study of Verbal Humor from the Perspective of Relevance Theory. Foreign Language Education, 1, 23-27.

Wei, N. X. (2002). Definition and Research of Collocation. Shanghai: Shanghai Jiao Tong University Press.

Wei, N. X. (2006). A Corpus-Based Contrastive Study of Semantic Prosodies in Learner English. Foreign Language Research, 5, 50-55. 